\title{
Infra-Red and vibration tests of hybrid ablative/ceramic matrix technological breadboards for earth re-entry thermal protection systems
}

\author{
Jorge Barcena ${ }^{a}{ }^{\text {, }}$, Iñaki Garmendia ${ }^{\mathrm{b}}$, Kostoula Triantou ${ }^{\mathrm{c}}$, Konstatina Mergia ${ }^{\mathrm{c}}$, Beatriz Perez ${ }^{\mathrm{a}}$, \\ Sonia Florez ${ }^{\mathrm{a}}$, Gregory Pinaud ${ }^{\mathrm{d}}$, Jean-Marc Bouilly ${ }^{\mathrm{d}}$ and Wolfgang P.P. Fischer ${ }^{\mathrm{e}}$
}

\begin{abstract}
a Industry and Transport Division, Tecnalia Research and Innovation, Mikeletegi Pasealekua 2, E-20009 Donostia-San Sebastian (Spain)

${ }^{b}$ Department of Mechanical Engineering, University of the Basque Country UPV/EHU, Engineering School of Gipuzkoa, Plaza de Europa, 1, 20018 Donostia-San Sebastian (Spain)

c Institute of Nuclear Technology and Radiation Protection N.C.S.R. "Demokritos", Aghia Paraskevi, 15310 Athens (Greece).

${ }^{d}$ Reentry Systems and Technologies Department, Airbus Safran Launchers SAS, Rue du Général Niox - BP 20011, 33165 Saint Médard en Jalles (France)

${ }^{e}$ Reentry Systems and Technologies Department, Airbus Safran Launchers GmbH, Airbus-Allee 1, D-28199 Bremen (Germany)
\end{abstract}

\begin{abstract}
A new thermal protection system for atmospheric earth re-entry is proposed. This concept combines the advantages of both reusable and ablative materials to establish a new hybrid concept with advanced capabilities. The solution consists of the design and the integration of a dual shield resulting on the overlapping of an external thin ablative layer with a Ceramic Matrix Composite (CMC) thermo-structural core. This low density ablative material covers the relatively small heat peak encountered during re-entry the $\mathrm{CMC}$ is not able to bear. On the other hand the big advantage of the CMC based TPS is of great benefit which can deal with the high integral heat for the bigger time period of the re-entry. To verify the solution a whole testing plan is envisaged, which as part of it includes thermal shock test by infra-red heating (heating flux up to $1 \mathrm{MW} / \mathrm{m}^{2}$ ) and vibration test under launcher conditions (Volna and Ariane 5). Sub-scale tile samples $\left(100 \times 100 \mathrm{~mm}^{2}\right)$ representative of the whole system (dual ablator/ceramic layers, insulation, stand-offs) are specifically designed, assembled and tested (including the integration of thermocouples). Both the thermal and the vibration test are analysed numerically by simulation tools using Finite Element Models. The experimental results are in good agreement with the expected calculated parameters and moreover the solution is qualified according to the specified requirements.
\end{abstract}

Keywords: thermal protection systems, atmospheric re-entry, ceramic matrix composite, infra-red tests, vibration tests, atmospheric re-entry, adhesives, joining, ablative material 


\section{Introduction}

Most of the actual commercial re-entry or space exploration missions rely on state of the art pure ablative material such as PICA (Phenolic Impregnated Carbon Ablator) [1]. On the other hand, reusable thermal protection systems (TPSs) based on the integration of ceramic matrix composites (CMCs) systems have been brought to flight maturity by extensive ground and flight testing and are now ready for application on re-entry missions typical to values of $1 \mathrm{MW} / \mathrm{m}^{2}$ and up to around 2.5 $\mathrm{MW} / \mathrm{m}^{2}$ maximum heat loads for a single use [2].

In order to withstand more and more severe oxidative and high temperature environment due to changing strategy and under increasingly demanding economical constraints, it worths to consider innovative solutions of TPS. Responding to new mission concepts for LEO or moon re-entry a new idea has been born extending the CMC based TPS to higher heat loads for such applications by integrating ablative material on the outer surface of the CMC [3, 4].

The use of CMC will offer lightness, improved mechanical properties as well as higher robustness during the entry. Besides, the new moon or interplanetary missions planned causes higher heat loads during earth re-entry than ceramic or metallic TPS can withstand, since these heat loads are characterized by a peak profile. These high heat loads of the peak profile can be borne by the ablative material. For that a comparatively thin layer of ablative material is sufficient. The large integral loads will then be overtaken by the ablative/ceramic interfacial layer [5].

The aim is to fabricate the hybrid ablative/ceramic structure, through adhesive bonding based on commercial high temperature inorganic adhesives is employed. In our previous work [6, 7] appropriate adhesives were selected based on the microstructural characteristics and the thermomechanical performance of the joints.

\section{Materials and methods}

\subsection{Materials}

The Ceramic Matrix Composite $(\mathrm{CMC})$ material $\mathrm{C}_{\mathrm{f}} / \mathrm{SiC}$, so-called $\mathrm{SiCARBON}^{\mathrm{TM}}$, and the ablative materials ASTERM ${ }^{\mathrm{TM}}$ and CALCARB ${ }^{\circledR}$ were used for the fabrication of the breadboard specimens. Ceramic matrix composite consisting of continuous carbon fibers embedded in $\mathrm{SiC}$ matrix $\left(\mathrm{C}_{\mathrm{f}} / \mathrm{SiC}\right.$, SiCARBON ${ }^{\mathrm{TM}}$ ) was fabricated as plates by Airbus Defence \& Space, Germany [8]. The fabrication of this material is based on the so-called Polymer Infiltration Pyrolysis (PIP) process. The infiltration of the carbon fibers with a pre-ceramic polymer-based and powder-filled slurry system is performed by Liquid Polymer Infiltration (LPI) via filament winding. The thickness of the $\mathrm{C}_{\mathrm{f}} / \mathrm{SiC}$ material used in the current study was $2.5 \mathrm{~mm}$.

ASTERM $^{\mathrm{TM}}$ ablative material, which was used for the Infra-Red test specimens, was fabricated by Airbus Defence \& Space, France. It consists of carbon fibers (55-80\%) and phenolic resin (20-45\%) 
$[9,10]$. It is manufactured by impregnating compacted graphite felt with phenolic resin, followed by a polymerisation process and final machining. The manufacturing approach allows a wide range of final material densities from 0.2 to $0.55 \mathrm{~g} / \mathrm{cm}^{3}$ and its decomposition point is about $235{ }^{\circ} \mathrm{C}$. Its porosity is between 75 and $80 \%$. The thickness of the material used in the study was 3 and $4 \mathrm{~mm}$. For the vibration test specimens, the ablative material CALCARB ${ }^{\circledR}$ (Commercial carbon substrate, similar to $\mathrm{ASTERM}^{\mathrm{TM}}$ or PICA preforms) was employed. It is made up from short cut carbon fibres, interconnected in a matrix produced by the carbonization of phenolic resin. Its bulk density is $0.18 \pm$ $0.03 \mathrm{~g} / \mathrm{cm}^{3}$ [11]. This non-pyrolyzing material is very similar to the rigid precursor of ASTERM ${ }^{\mathrm{TM}}$ and serves as an ideal candidate to decouple the physico-chemical phenomena of heterogeneous pyrolysis gas chemistry and carbon fiber/char ablation for fundamental ablation experiments [12]. CALCARB $®$ was also used in previous related studies [5;Error! Marcador no definido., 13], in which the thermal shock performance of ablative/ceramic structure was investigated.

The selection of the most suitable adhesives for the joints was based on a) the curing temperature that has to be below the ablator decomposition temperature (approximately $150-200{ }^{\circ} \mathrm{C}$ ) and b) the fact that they have to withstand very high temperatures reached during the re-entry. These factors imposed the use of inorganic adhesives. For the joining of CMC and ablative material, the commercial inorganic adhesives Ceramabond ${ }^{\mathrm{TM}} 835\left(\mathrm{ZrO}_{2}-\mathrm{ZrSiO}_{4}\right.$-based) and Graphibond ${ }^{\mathrm{TM}} 669$ (graphite-based) were used. These two adhesives were selected after an initial screening of six commercial inorganic adhesives based on alumina, zirconia-zirconium silicate and graphite having high and low viscosities.

The screening was performed employing pull off tests and microstructure investigation of the interfaces. Furthermore, this selection was based on the results of the previous studies $[5,6,13]$ employing thermal shock tests as well as mechanical tests at liquid nitrogen, room and elevated temperatures. The adhesives were supplied from Aremco Products, Inc. Their properties and composition are presented in Table 1.

Table 1. Identification, composition and properties of adhesives [14].

\begin{tabular}{|c|c|c|}
\hline Tradename & 669 Graphi-Bond $^{\mathrm{TM}}$ & 835 Ceramabond $^{\mathrm{TM}}$ \\
\hline Description & $\begin{array}{c}\text { Black, viscous and } \\
\text { odorless paste }\end{array}$ & Tan, viscous and odorless paste \\
\hline FILLER, Major Constituent & Graphite & $\mathrm{ZrO}_{2}-\mathrm{ZrSiO}_{4}$ \\
\hline Ingredients & $\begin{array}{l}\text { Graphite, Aluminium } \\
\text { oxide, silicate solution }\end{array}$ & $\begin{array}{l}\text { Zirconium oxide, zirconium } \\
\text { silicate, aluminium-silicate, } \\
\text { silicate solution }\end{array}$ \\
\hline Viscosity, cP & $20,000-40,000$ & $20,000-40,000$ \\
\hline Density, $\mathrm{g} / \mathrm{cm}^{3}$ & $1.45-1.50$ & $2.25-2.35$ \\
\hline Temperature Use Limit, $\left({ }^{\circ} \mathrm{C}\right)$ & 760 & 1371 \\
\hline CTE $\left(\times 10^{-6} \mathrm{~K}^{-1}\right)$ & 7.6 & 7.2 \\
\hline
\end{tabular}




\subsection{Fabrication and design requirements of specimens for Infra-Red tests}

Breadboards were designed and constructed for the Infra-Red (IR) tests (Figure 1), so as to reproduce as close as possible the temperature profile of the ablator/CMC dual layer interface and check the thermal behaviour of the hybrid tile. Four specimens were fabricated with graphite-based and $\mathrm{ZrO}_{2}-\mathrm{ZrSiO}_{4}$-based adhesives for the CMC-ablative material joining (two specimens for each adhesive). Depending on the used adhesive, different thickness of ablative material was used, $4 \mathrm{~mm}$ for graphite adhesive and $3 \mathrm{~mm}$ for $\mathrm{ZrO}_{2}-\mathrm{ZrSiO}_{4}$ adhesive in order to tune the maximum interfacial temperature to the maximum service temperature of each adhesive. As shown in Figure 1, the IR specimen is fully representative of an operational tile and is composed of:

- ASTERM $^{\mathrm{TM}}$ ablative material (thickness 3 or $4 \mathrm{~mm}$ )

- Graphite-based or $\mathrm{ZrO}_{2}-\mathrm{ZrSiO}_{4}$-based adhesive $(0.2 \mathrm{~mm})$

- $\mathrm{SiCARBON}^{\mathrm{TM}} \mathrm{CMC}$ material $(2.5 \mathrm{~mm})$

- Internal Flexible Insulation (IFI) (40 mm)

- Four stand-offs made of Ti6Al4V grade 5 alloy

- Aluminium plate (2 mm)
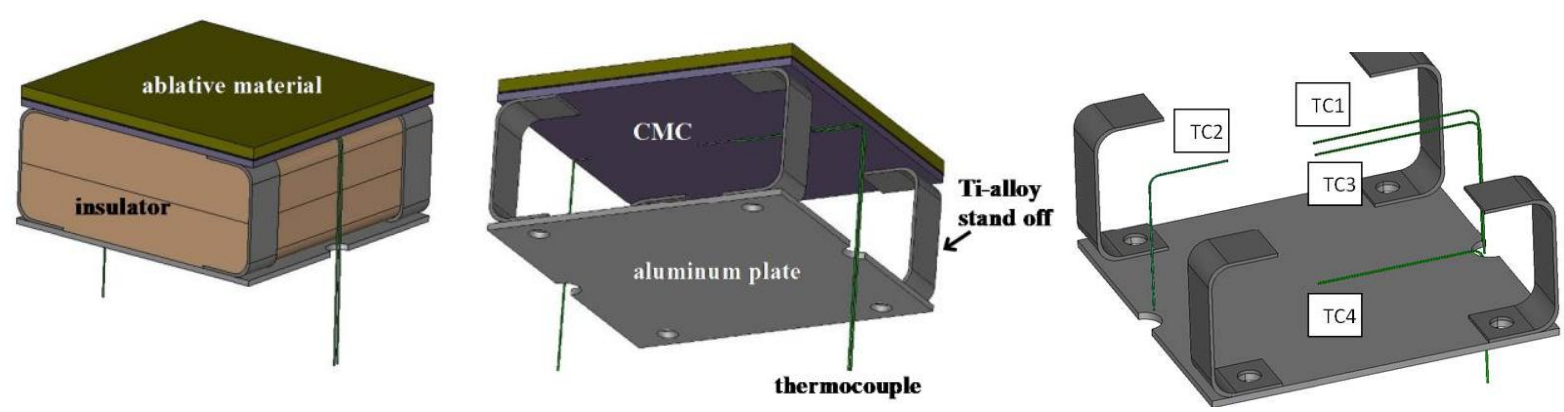

Figure 1. IR specimen definition concept and its instrumentation with thermocouples (TC).

The fabrication procedure includes the following steps:

- Brazing of the stand-offs to the CMC

- Placement of the thermocouples

- Placement of insulator material

- Joining of ablator to CMC

The first step for the fabrication of the specimens was the joining of four " $U$ " shape Ti6Al4V stand-offs at the corners of the CMC plate using the technology developed in [15]. Due to the temperature limit of the Ti6Al4V, this design and material choice is particularly suitable for the breadboards and for the final component a material trade-off should be carried-out. For this purpose, brazing was employed and the CMCs were previously perforated at the brazing area with holes of 0.95 
and $0.65 \mathrm{~mm}$ depth and $1.0 \mathrm{~mm}$ diameter. The brazing material was TiCuAg foils and a jig was constructed to ensure the proper alignment of the pieces. The brazing area of the stand-off was $15 \mathrm{x}$ $15 \mathrm{~mm}^{2}$. In only few cases a final polishing of the stand-off at the edges area was necessary after brazing. Subsequently, four thermocouples were placed to defined positions presented in Table 2, Table 3 and shown in Figures 1 and 2. The thermocouples were used to check the suitability of the IR incident flux, to control the temperature at the ablator-CMC interface and its homogeneity as well as to confirm the selection of the insulator for its thermal performance.

Table 2. Thermocouple location for IR specimen.

\begin{tabular}{|l|l|}
\hline Thermocouple (TC) reference & Position \\
\hline TC1 & middle of the CMC plate (top face) \\
\hline TC2 & quarter of the median (25 mm from the edge) (top face) \\
\hline TC3 & middle of the CMC plate (back face) \\
\hline TC4 & middle of the aluminum plate (top face) \\
\hline
\end{tabular}

(a)

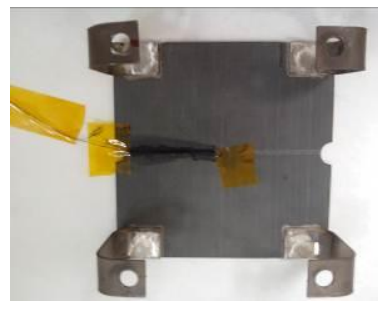

(b)

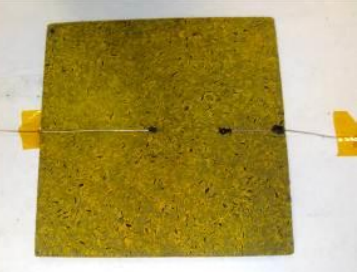

(c)

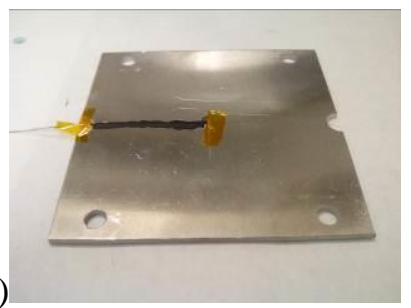

Figure 2. Placement of the thermocouples in the parts of IR breadboard specimen: (a) CMC plate with stand-offs, (b) ablative material and (c) aluminum plate.

Table 3. Depth and diagonal location of thermocouples (TC) for the IR specimens.

\begin{tabular}{|c|c|c|c|}
\hline Specimens & TC Reference & $\begin{array}{c}\text { TC depth } \\
\text { (mm from outer face) }\end{array}$ & $\begin{array}{c}\text { TC off-center distance } \\
(\mathbf{m m})\end{array}$ \\
\hline \multirow{3}{*}{$\begin{array}{c}\text { Graphite-based } \\
\text { adhesive }\end{array}$} & $\mathrm{TC} 1$ & 4 & 0 \\
\cline { 2 - 4 } & $\mathrm{TC} 2$ & 4 & 30 \\
\cline { 2 - 4 } & $\mathrm{TC} 3$ & 6.5 & 0 \\
\hline \multirow{3}{*}{$\begin{array}{l}\mathrm{ZrO}_{2}-\mathrm{ZrSiO}_{4}- \\
\text { based adhesive }\end{array}$} & $\mathrm{TC} 4$ & 46.5 & 0 \\
\cline { 2 - 4 } & $\mathrm{TC} 1$ & 3 & 30 \\
\cline { 2 - 4 } & $\mathrm{TC} 2$ & 3 & 0 \\
\hline
\end{tabular}


The next step of the fabrication procedure includes the placement of insulator. The insulator of IFI type is chosen for its high thermal performance and its low aerial weight (Figure 3). The IFI blankets can withstand high temperature (up to $1300{ }^{\circ} \mathrm{C}$ ), have a very low conductivity and low density (approximately $120 \mathrm{~kg} / \mathrm{m} 3$ ). The density of such blanket made of short alumina fibers can be easily tuned to the desired values.

The full size IFI insulation panels $\left(300 \times 300 \mathrm{~mm}^{2}\right)$ are completely embedded in ceramic textiles (covering the 6 sides). These panels are stitched in the $\mathrm{Z}$ axis to improve the fixations micro-fibres that are kept inside the panel. For the preparation of the technological bread, sections of those panel have been cut on sizes of $99 \times 99 \mathrm{~mm}^{2}$, leaving the lateral sides uncovered.

Each IR specimen has two pieces $(99$ x $99 \mathrm{~mm} 2)$ of IFI which were placed between the aluminum plate and CMC (Figure 4b). Initially, the two pieces of insulator were covered with a plastic film in order to avoid potential damages. After the placement, this film was removed. The fabrication of specimens was completed with the joining of CMC with the ablative material on top (Figure 4c). The graphite-based and $\mathrm{ZrO}_{2}-\mathrm{ZrSiO}_{4}$-based adhesives were applied at CMC top bonding surface. The specimens were cured in an oven at $93{ }^{\circ} \mathrm{C}$ for 2 hours, applying some pressure to ensure a good contact during the curing.
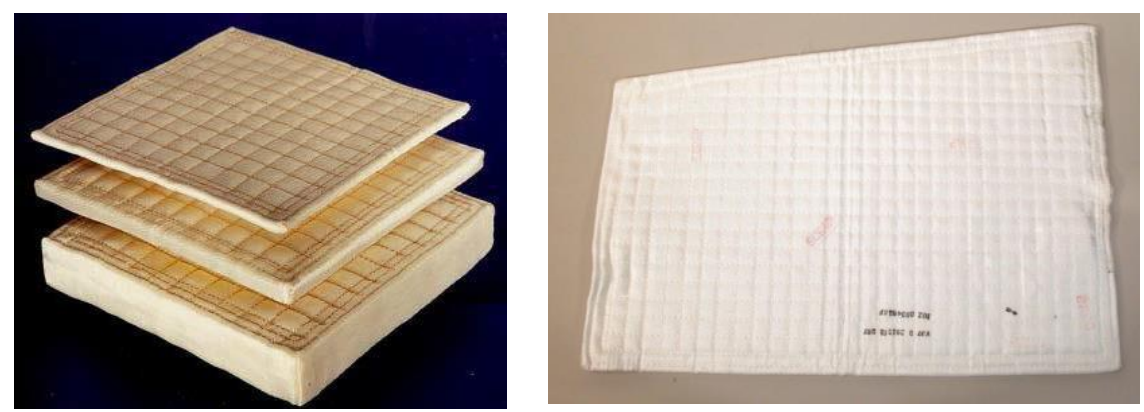

Figure 3. Internal Flexible Insulation (IFI) blankets of different thickness (courtesy of Airbus Safran Launchers GmbH).

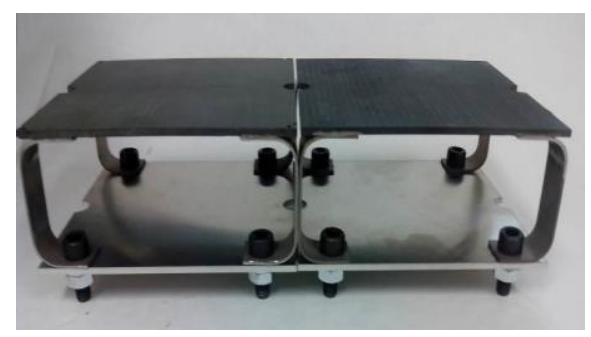

(a)

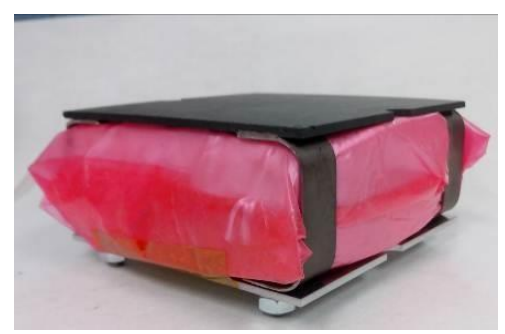

(b)

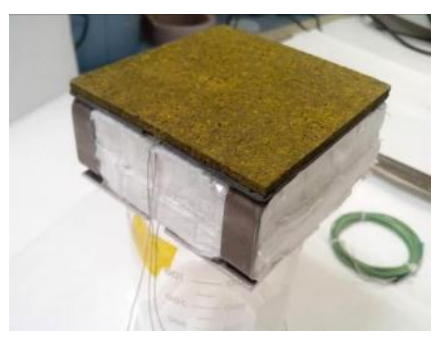

(c)

Figure 4. IR breadboard specimen: (a) CMC plate, stand-offs and aluminum plate, (b) insulator allocation and (c) specimen fabrication completed.

\subsection{Infra-Red tests}


Infra-Red (IR) tests in this study were performed on larger specimens than those used for the thermal shock tests and for the mechanical tests of the previous studies $[3,4,13]$. Specifically, the size of the bonded area was $100 \times 100 \mathrm{~mm}^{2}$, the maximum size allowed by the specimen holder, cooling system and IR lamp maximum radiative power (Figure 5). The IR tests of these breadboards allow the characterization of the hybrid TPS in a near-flight configuration. The thermal behaviour of the hybrid TPS regarding the differential thermal expansion coefficient was experimentally investigated. Also, the strength of the interface even when the ablative material (ASTERM ${ }^{\mathrm{TM}}$ ) is in a charred state was validated. The temperature values reached at the adhesive zone were $700{ }^{\circ} \mathrm{C}$ for the graphite-based adhesive and $1000{ }^{\circ} \mathrm{C}$ for the $\mathrm{ZrO}_{2}-\mathrm{ZrSiO}_{4}$-based adhesive. The maximum radiative heat flux delivered by the IR lamps was $600 \mathrm{~kW} / \mathrm{m}^{2}$. The target temperature at the bonding interface can be reached by tuning the exposure duration of the tests and the thickness of the ablator. For each of the bonding adhesive (graphite-based and $\mathrm{ZrO}_{2}-\mathrm{ZrSiO}_{4}$-based) the duration was specified in order to reach the target temperature. By simulation, a preliminary duration has been proposed: $60 \mathrm{~s}$ for graphite and $100 \mathrm{~s}$ for $\mathrm{ZrO}_{2}-\mathrm{ZrSiO}_{4}$ adhesive.
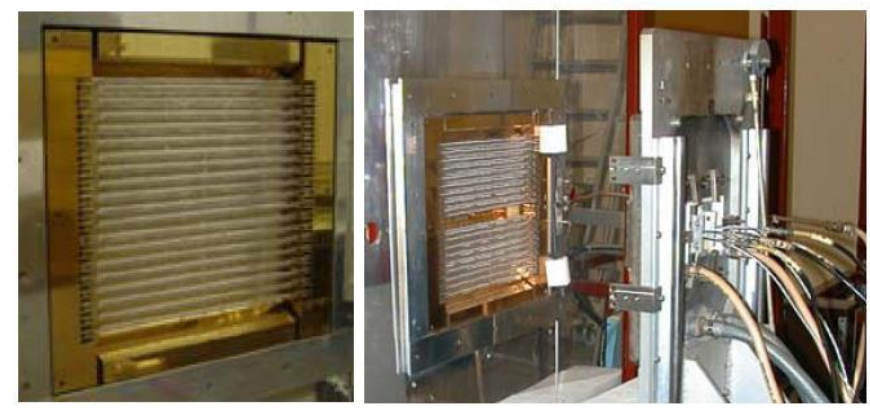

Figure 5. Side views of the IR lamp and furnace.

\subsection{Fabrication of specimens for vibration tests}

Following the same procedure and design as for the IR specimens (\$2.2), two breadboard specimens were fabricated for the vibration tests (one for each adhesive). The ablative material selected was CALCARB ${ }^{\circledR}$ as explained in $\S 2.1$. The ablator thickness was $4 \mathrm{~mm}$ and both adhesives were used. The vibration specimens after the assembly are shown in Figure 6. The specimens were tested under the conditions of Russian Volna launcher and Ariane 5. 


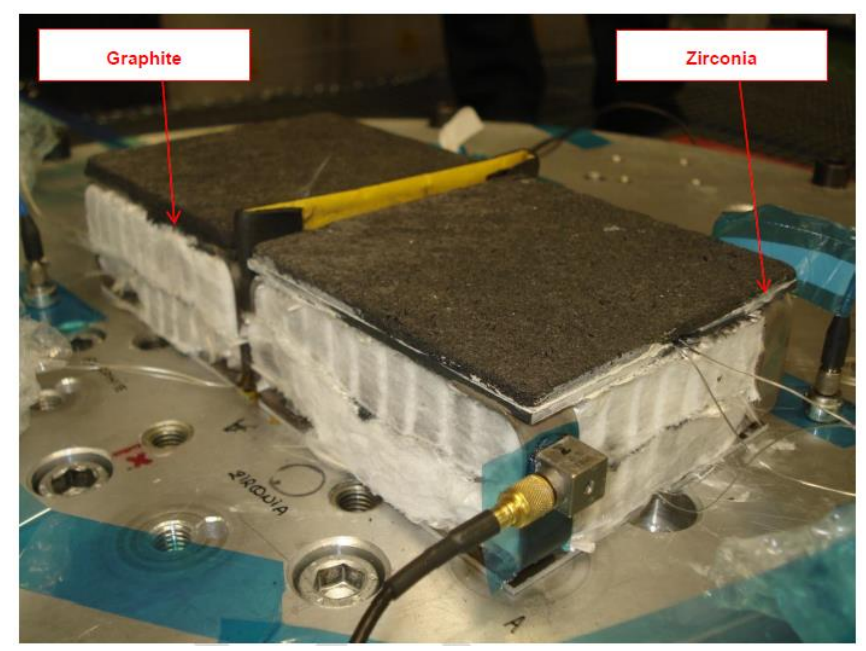

Figure 6. Vibration tests specimens.

\subsection{Vibration tests}

Vibration tests were performed following the CTA (Centro de Tecnologías Aeronáuticas) Operative Instruction (under standard ECSS-E-ST-10-03-C) and the requirements given in Table 4, in which vibration and acoustic noise requirements for the three main launchers Volna, Vega and Ariane 5 SG (A5-SG) are included. The spectral density for both in and out of plane loading against a frequency range for different launchers is presented in Table 4. As starting condition the less demanding Volna specifications were selected, although as the breadboard survived (both in-plane: $\mathrm{X}$ and Y and out of plane profiles: Z), the Ariane 5 SG specification (only in-plane: X) were also used for a final test. Two breadboards having the same design and fabricated with the same procedure as the IR breadboards, were used for the vibration tests. One breadboard was assembled with $\mathrm{ZrO}_{2}-\mathrm{ZrSiO}_{4^{-}}$ based adhesive and the other one with graphite-based adhesive (Figure 6). A rubber spacer was placed in-between the breadboard to avoid potential collision on the $\mathrm{X}$ axis vibration (worse stand-off configuration).

Table 4. Specifications of Volna, Vega and Ariane 5 SG launchers. The conditions of Volna and Ariane $5 \mathrm{SG}$ are used for the vibration tests.

\begin{tabular}{|c|c|c|c|c|c|c|}
\hline $\begin{array}{c}\text { Frequency } \\
{[\mathbf{H z}]}\end{array}$ & \multicolumn{2}{|c|}{ Spectral Density (in-plane loading) } & \multicolumn{3}{|c|}{$\begin{array}{c}\text { Spectral Density (out-of-plane loading) } \\
{\left[\mathbf{g}^{2} / \mathbf{H z} / \mathbf{H z}\right]}\end{array}$} \\
\hline & Volna & $\begin{array}{c}\text { Vega } \\
\text { (flight/qual) }\end{array}$ & A5-SG & Volna & $\begin{array}{c}\text { Vega } \\
\text { (flight/qual) }\end{array}$ & A5-SG \\
\hline 20 & 0.0004 & $0.0001 / 0.000414$ & 0.0913 & 0.0004 & $0.0001 / 0.000414$ & 0.0913 \\
\hline 60 & 0.00828 & & 0.2730 & & & 0.2730 \\
\hline 80 & & $0.12 / 0.49$ & & & $0.013 / 0.0538$ & \\
\hline 100 & & & & 0.1656 & & \\
\hline 400 & 0.00828 & & & 0.1656 & & \\
\hline 600 & & $0.12 / 0.49$ & & & $0.013 / 0.0538$ & \\
\hline 1000 & & & 0.2730 & & & 0.2730 \\
\hline 2000 & 0.0004 & $0.001 / 0.000414$ & 0.0690 & 0.0004 & $0.0002 / 0.000828$ & 0.0690 \\
\hline
\end{tabular}


An adaptor was fabricated to allocate and attach the breadboard at the middle position of the shaker and M6 bolts with anti-blocking system were used. The breadboard also included the corresponding thermocouples in order to verify its attachment under vibrations.

The vibration system (LDS V984 shaker with TEAM slip table) of $1200 \times 1200 \mathrm{~mm}^{2}$ dimensions was operated in 5 to $2000 \mathrm{~Hz}$ frequency range and allowed for $160 \mathrm{kN}$ force and $100 \mathrm{~g}$ maximum acceleration.

The control of the input excitation was carried out using two pilot accelerometers in each test, according to the following strategy: the input level was defined by the average value of the pilot accelerometers. One triaxial accelerometer was placed in each breadboard in order to measure the acceleration response (attached to the back of the Ti-alloy stand-off) (Table 5, Figure 7).

Table 5. Position and axes of accelerometers.

\begin{tabular}{|l|c|c|c|c|}
\hline \multirow{2}{*}{ ID CTA } & \multirow{2}{*}{ Fuction } & \multirow{2}{*}{ Position } & \multicolumn{2}{|c|}{ Axes } \\
\cline { 4 - 5 } & & & $\begin{array}{c}\text { Accelerometer } \\
\text { Axes }\end{array}$ & Specimen Axes \\
\hline ACL096 & Control & $\mathrm{C} 1$ & 1 & Test axis \\
\hline ACL097 & Control & $\mathrm{C} 2$ & 1 & Test axis \\
\hline ACL028 & Measurement & $\mathrm{A}$ & 1 & $\mathrm{Y}$ \\
& & & 2 & $\mathrm{Z}$ \\
& & & 3 & $\mathrm{X}$ \\
\hline ACL029 & Measurement & $\mathrm{B}$ & 1 & $\mathrm{Y}$ \\
& & & 2 & $\mathrm{Z}$ \\
& & & 3 & $\mathrm{X}$ \\
\hline
\end{tabular}

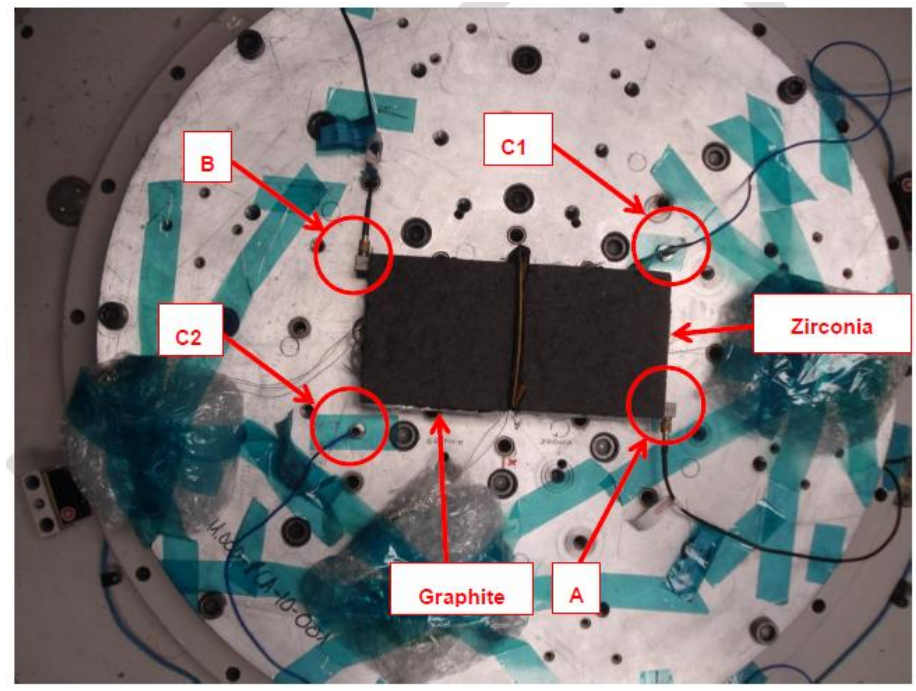

Figure 7. Positions of accelerometers.

The specimens were installed on the shaker and tested according to the CTA test protocol (in accordance with ECSS-E-ST-10-03-C standard). It was undergone to low sweep sine and different 
levels of random vibration tests, along three orthogonal axes, $\mathrm{X}, \mathrm{Y}$ and $\mathrm{Z}$. The level for sine vibration according to the specifications is presented in Table 6, Table 7 and

Table 8 .

Table 6. Sine low level.

\begin{tabular}{|c|c|}
\hline \multicolumn{2}{|c|}{$\mathbf{Z}, \mathbf{Y}$ and $\mathbf{X}$ axes } \\
\hline Frequency Band $(\mathrm{Hz})$ & Low Level \\
\hline $5-2000$ & $0.5(\mathrm{~g})$ \\
\hline Sweep rate & $2 \mathrm{oct} / \mathrm{min}$ \\
\hline
\end{tabular}

Table 7. Random test levels during $\mathrm{Z}, \mathrm{Y}$ and $\mathrm{X}$ axes (Volna levels).

\begin{tabular}{|c|c|c|c|c|}
\hline axis & Frequency Band $(\mathrm{Hz})$ & \multicolumn{2}{|c|}{ Intermediate level } & Full level \\
\hline \multirow{6}{*}{$\mathbf{Z}$} & 20 & \multirow{4}{*}{$-12 \mathrm{~dB}$} & \multirow{4}{*}{$-6 \mathrm{~dB}$} & $0.0004 \mathrm{~g}^{2} / \mathrm{Hz}$ \\
\hline & 100 & & & $0.1656 \mathrm{~g}^{2} / \mathrm{Hz}$ \\
\hline & 400 & & & $0.1656 \mathrm{~g}^{2} / \mathrm{Hz}$ \\
\hline & 2000 & & & $0.0004 \mathrm{~g}^{2} / \mathrm{Hz}$ \\
\hline & Overall level & $2.2 \mathrm{grms}$ & $8.77 \mathrm{grms}$ & $4.39 \mathrm{grms}$ \\
\hline & Duration & $30 \mathrm{~s}$ & $120 \mathrm{~s}$ & $30 \mathrm{~s}$ \\
\hline \multirow{6}{*}{$\begin{array}{c}\mathbf{Y} \\
\text { and } \\
\mathbf{X}\end{array}$} & 20 & \multirow{4}{*}{ - } & \multirow{4}{*}{$-6 \mathrm{~dB}$} & $0.0004 \mathrm{~g}^{2} / \mathrm{Hz}$ \\
\hline & 100 & & & $0.00828 \mathrm{~g}^{2} / \mathrm{Hz}$ \\
\hline & 400 & & & $0.00828 \mathrm{~g}^{2} / \mathrm{Hz}$ \\
\hline & 2000 & & & $0.0004 \mathrm{~g}^{2} / \mathrm{Hz}$ \\
\hline & Overall level & - & $2.4 \mathrm{grms}$ & 2.4 grms \\
\hline & Duration & - & $120 \mathrm{~s}$ & $30 \mathrm{~s}$ \\
\hline
\end{tabular}

Table 8. Random test levels during $X$ axis (Ariane 5).

\begin{tabular}{|c|c|c|}
\hline \multicolumn{3}{|c|}{ X axis (A5-SG levels) } \\
\hline Frequency Band (Hz) & Intermediate level & Full level \\
\cline { 1 - 1 } 20 & & $0.0913 \mathrm{~g}^{2} / \mathrm{Hz}$ \\
\cline { 1 - 1 } 100 & \multirow{3}{*}{$-6 \mathrm{~dB}$} & $0.273 \mathrm{~g}^{2} / \mathrm{Hz}$ \\
& & $0.273 \mathrm{~g}^{2} / \mathrm{Hz}$ \\
\hline 200 & $10.03 \mathrm{grms}$ & $0.069 \mathrm{~g}^{2} / \mathrm{Hz}$ \\
\hline Overall level & $120 \mathrm{~s}$ & $30 \mathrm{grms}$ \\
\hline Duration & &
\end{tabular}


Also, the tests performed and the sequence followed in each case, are shown in ¡Error! La autoreferencia al marcador no es válida.

Table 9. Test sequence.

\begin{tabular}{|c|c|c|}
\hline TEST BREADBOARD & TEST AXIS & TEST DESCRIPTION \\
\hline \multirow{20}{*}{$\mathrm{ZrO}_{2}-\mathrm{ZrSiO}_{4}$-based adhesive } & \multirow{6}{*}{$\mathrm{Z}$ Axis Test } & Low Sine \\
\hline & & Random -12dB (Volna) \\
\hline & & Random -6dB (Volna) \\
\hline & & Low Sine \\
\hline & & Random Full test (Volna) \\
\hline & & Low Sine \\
\hline & \multirow{5}{*}{ Y Axis Test } & Low Sine \\
\hline & & Random -6dB (Volna) \\
\hline & & Low Sine \\
\hline & & Random Full test (Volna) \\
\hline & & Low Sine \\
\hline & \multirow{9}{*}{ X Axis Test } & Low Sine \\
\hline & & Random -6dB (Volna) \\
\hline & & Low Sine \\
\hline & & Random Full test (Volna) \\
\hline & & Low Sine \\
\hline & & Random -6dB (A5-SG) \\
\hline & & Low Sine \\
\hline & & Random Full test (A5-SG) \\
\hline & & Low Sine \\
\hline
\end{tabular}

\subsection{Simulation tools}

Thermo-ablative analysis of lightweight charring ablator are performed by the standard Airbus DS tool SAMCEF-AMARYLLIS [16]. This finite element analysis software is used in any phase of 
Airbus DS project from very preliminary design up to spacecraft or launcher final qualification. AMARYLLIS is a numerical tool developed and distributed by the company SIEMENS-SAMTECH (Belgium), which is technically supported by the University of Liège. This code is one of the various modules of SAMCEF. Therefore, it benefits from all the user environment of SAMCEF (mesh, data, pre-processor \& post-processor, direct or staggered coupling with other SAMCEF modules (mechanical), version follow up \& maintenance...).

The computer code employed for the FEM simulation is SOLVIA, from Solvia Engineering AB, Vasteras, Sweden. The program is a powerful tool for solving linear and non linear problems, both for stress analysis and for heat transfer. The program has also some tools for mesh generation, which were used to develop the mesh employed in the vibrations analysis. The vibration modes and their correspondent frequencies were determined trough the subspace iteration method, without applying the Sturm sequence check. Limited graphics capabilities are also present in the program, which were used to produce figures 15 and 16 .

\section{Results and discussion}

\subsection{Infra-Red tests}

\subsubsection{Numerical simulation}

A simple 1D model of the whole stack of materials is built and a simulation was run using the FEM code Amaryllis and the thermochemical model of ASTERM ${ }^{\mathrm{TM}}$. The 1D model is schematically presented in Figure 8 and therefore cannot account for the heat sink in the stand-off. However, due to the small interface area of the stands-off and their off-centred positions, it is assumed that the thermal perturbation can be neglected with regard to the global performance of the system for this experiment.

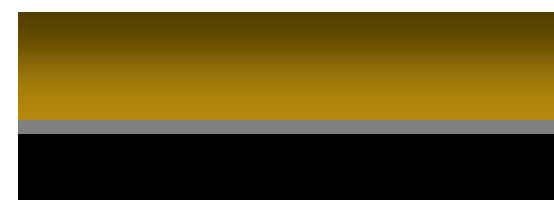

$\operatorname{ASTERM}(4-3 \mathrm{~mm})$

ADHESIVE $(0.2 \mathrm{~mm})$

SICARBON ( $2.5 \mathrm{~mm})$

IFI ( $40 \mathrm{~mm})$

Alu $2 \mathrm{~mm}$

Figure 8. Scheme of the IR specimen 1D model.

The pseudo thermocouples measurements are reported in Figure 9 for two values of ablator thickness to assess the sensitivity of the temperature at the bonding interface with the potential 
manufacturing dispersions. The predicted temperature at the outer surface shows only small dependencies on the ASTERM ${ }^{\mathrm{TM}}$ thickness and is below $1450{ }^{\circ} \mathrm{C}$ after $60 \mathrm{~s}$ of radiative exposure. The temperature at the CMC/ablator interface is about $770{ }^{\circ} \mathrm{C}$ after $60 \mathrm{~s}$ of exposure for the case of $4 \mathrm{~mm}$ ASTERM $^{\mathrm{TM}}$ thickness and the decrease of the ASTERM ${ }^{\mathrm{TM}}$ thickness by $1 \mathrm{~mm}$ results in about $130{ }^{\circ} \mathrm{C}$ temperature increase. The predicted temperature of the aluminium plate substructure is quite independent on the ASTERM ${ }^{\mathrm{TM}}$ thickness and stays below $180{ }^{\circ} \mathrm{C}$.

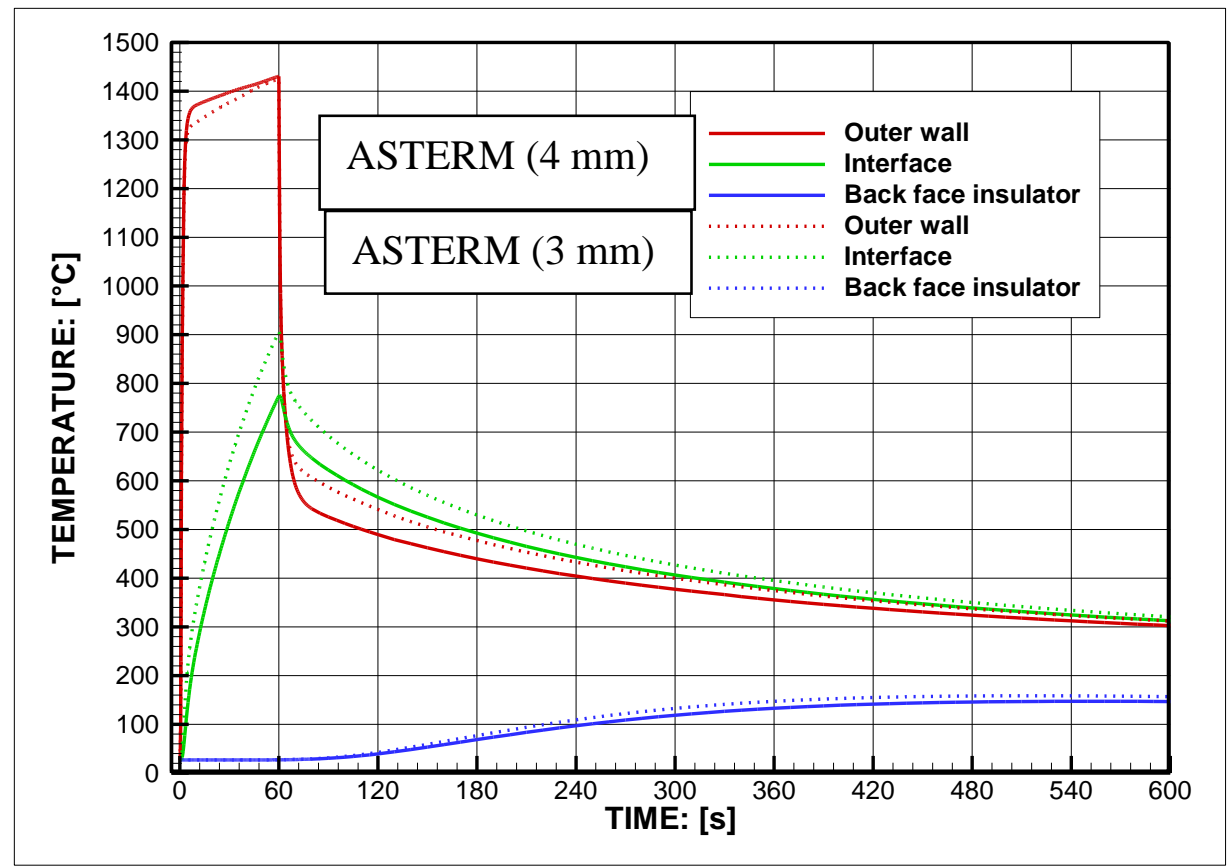

Figure 9. Prediction of temperature history at different depth by virtual thermocouples.

\subsubsection{Experimental validation}

Under the conditions described in $\S 2.3$ the breadboards with the two adhesives were successfully tested. The characteristics of the three IR tests and post-test measurements are given in Table 10.

Table 10. Characteristics of the performed IR tests.

\begin{tabular}{|c|c|c|c|}
\hline $\begin{array}{c}\text { Breadboard } \\
\text { reference }\end{array}$ & $\begin{array}{c}\text { Test duration } \\
(\mathbf{s})\end{array}$ & $\begin{array}{c}\text { Maximum temperature } \\
\text { at bondline }\left({ }^{\mathbf{O}} \mathbf{C}\right)\end{array}$ & $\begin{array}{c}\text { Mass } \\
\text { loss }(\mathbf{g})\end{array}$ \\
\hline $\begin{array}{c}\text { Graphite-based } \\
\text { adhesive }\end{array}$ & 60 & 777 & 7.0 \\
\hline $\begin{array}{c}\mathrm{ZrO}_{2}-\mathrm{ZrSiO}_{4^{-}} \\
\text {based adhesive, } \\
\text { specimen 1 }\end{array}$ & 60 & 856 & 2.6 \\
\hline $\begin{array}{c}\mathrm{ZrO}_{2}-\mathrm{ZrSiO}_{4^{-}} \\
\text {based adhesive, } \\
\text { specimen 2 }\end{array}$ & 100 & 1100 & 4.4 \\
\hline
\end{tabular}

For the graphite-based adhesive breadboard, the wall temperature (measured with a pyrometer calibrated with emissivity 1 for the ablator) shows similar response to the simulation once scaled to a 
more appropriate emissivity for charred $\mathrm{ASTERM}^{\mathrm{TM}}$ (estimated at 0.8 ). The measured temperature at the bonding interface seems to be spatially very homogeneous (less than $50{ }^{\circ} \mathrm{C}$ difference). Similarly, there is only low gradient through the CMC. This was also expected considering the thermal conductivity of the material and its small thickness. More than 13 minutes after the test, the back face temperature (at the aluminium plate depth), increases up to $37{ }^{\circ} \mathrm{C}$ before starting to decline back to the room temperature. The total mass loss of the hybrid graphite-based adhesive breadboard is $7 \mathrm{~g}$. No recession has been observed during the test. If it is assumed that ASTERM ${ }^{\mathrm{TM}}$ is fully charred after the test, the contribution of pyrolysis to this mass loss would have been of $1.9 \mathrm{~g}$. The remaining mass loss can therefore be explained by the mass loss of the adhesive (by pyrolysis) and water evaporation from the IFI.

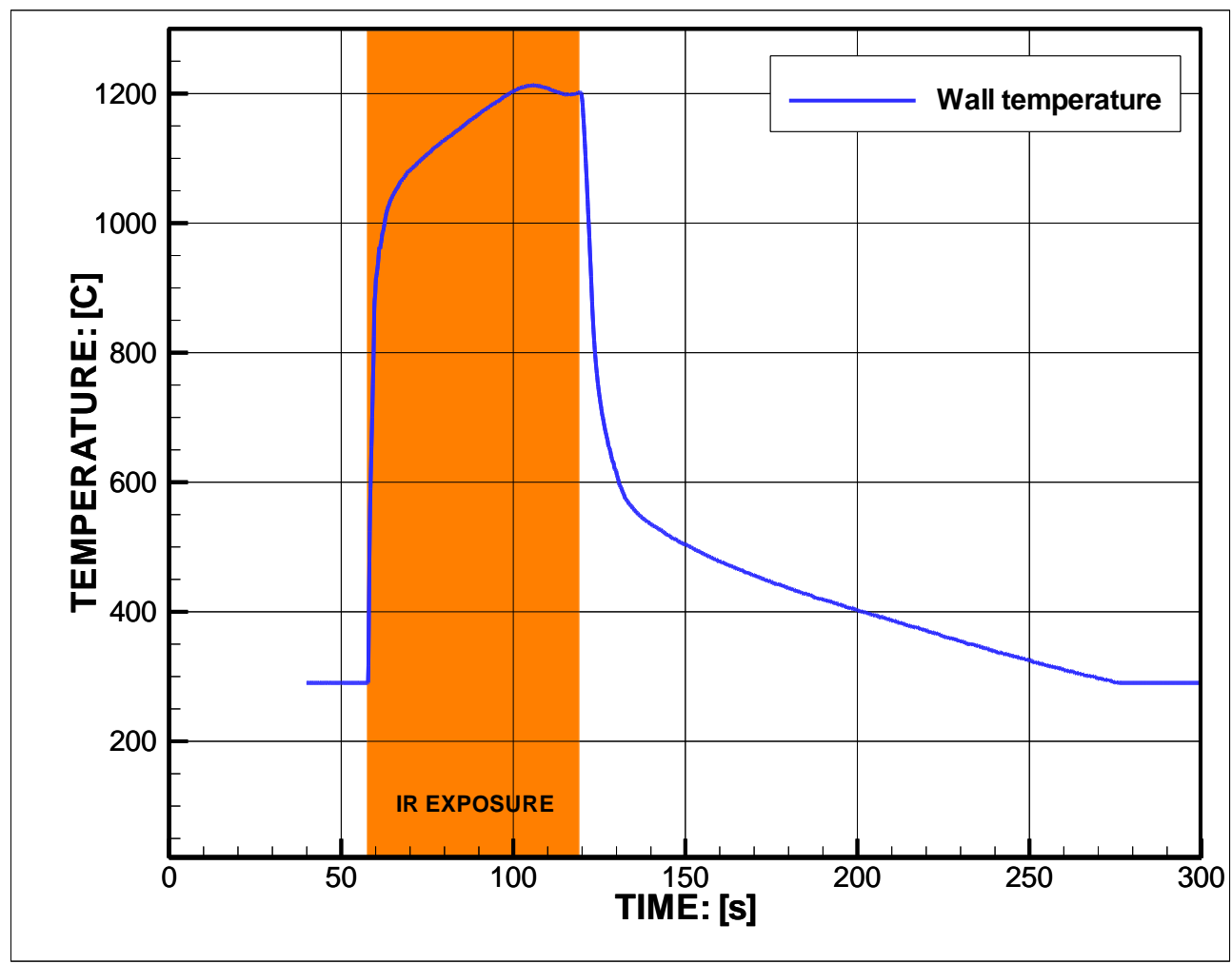

Figure 10. Temperature at the outer surface (outer wall) for the graphite-based adhesive breadboard measured with a pyrometer with emissivity 1 for the ablator. 


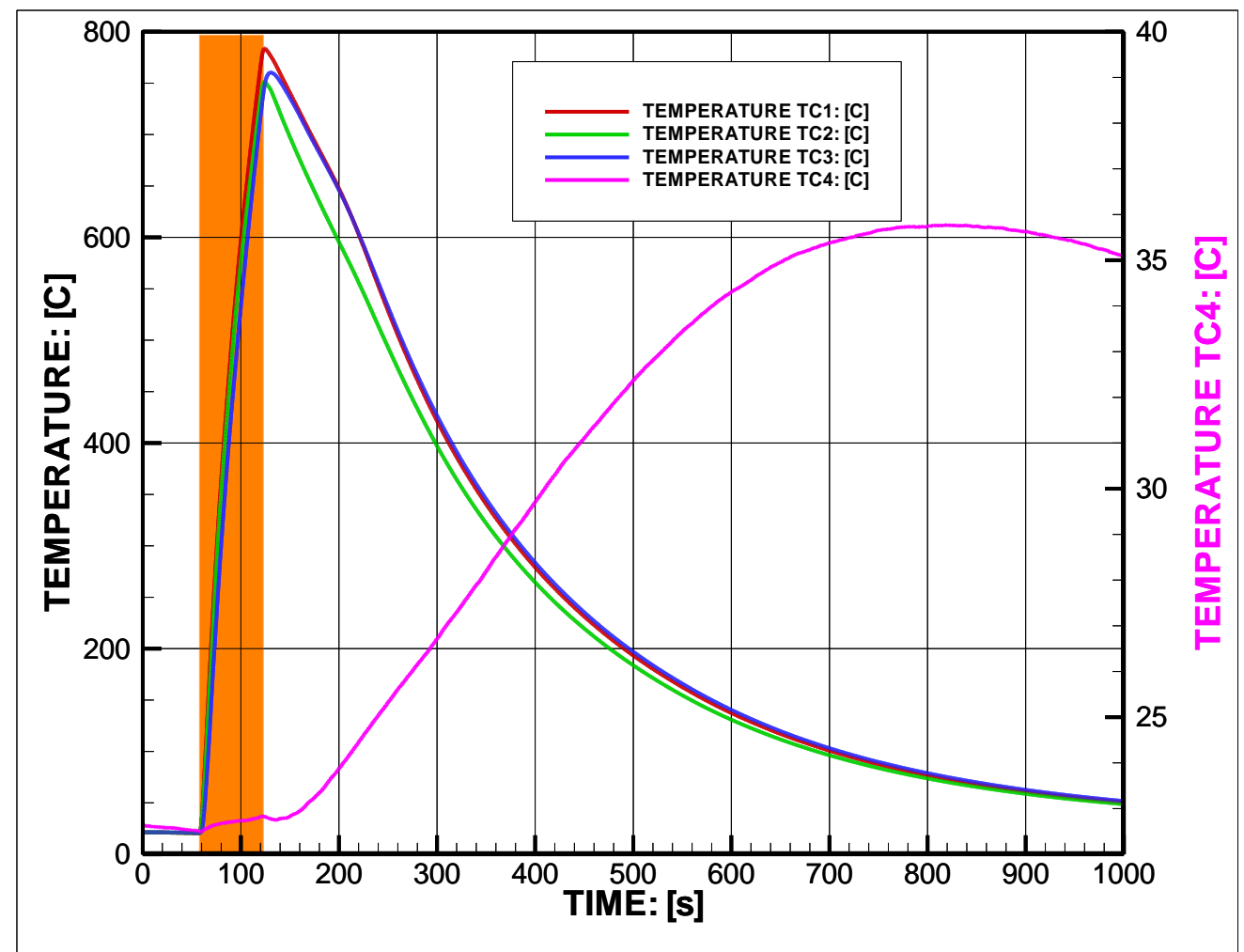

Figure 11. Measured temperature for the graphite-based adhesive hybrid specimen.

The hybrid graphite-based adhesive breadboard before and after the radiative exposure is shown in Figure 12. As expected, the yellowish colour of ASTERM ${ }^{\mathrm{TM}}$ turns to a black carbonaceous, witnessing the effect of pyrolysis of the ablative material. No debonding was observed, but it is difficult to conclude because of the lack of external representative mechanical loads.

(a)

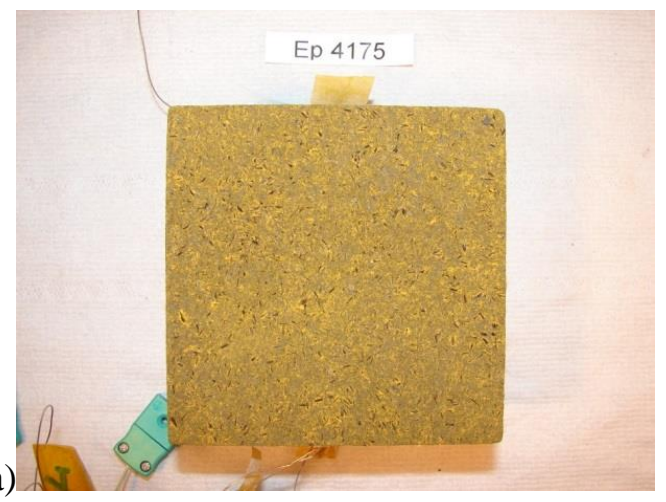

(b)

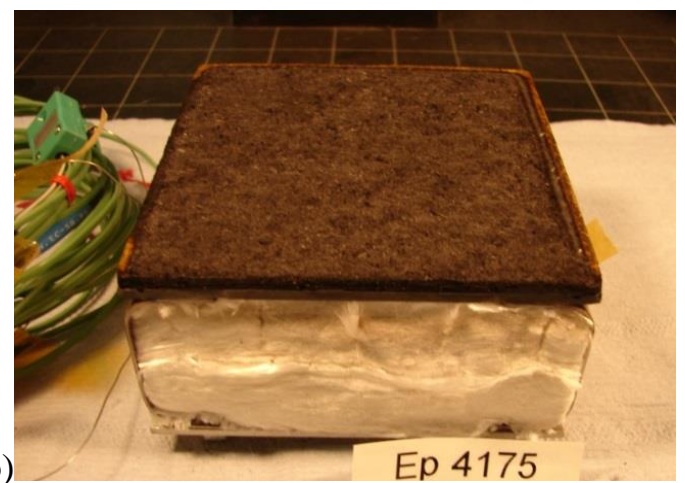

Figure 12. Pre (a) and post (b) test pictures of the graphite-based adhesive hybrid breadboard.

The $3 \mathrm{~mm}$ thickness of $\mathrm{ASTERM}^{\mathrm{TM}}$ on the $\mathrm{ZrO}_{2}-\mathrm{ZrSiO}_{4}$-based adhesive hybrid specimen $\mathrm{N}^{\mathrm{o}} 2$ associated to a $60 \mathrm{~s}$ test duration was not sufficient to reach the target temperature for $\mathrm{ZrO}_{2}-\mathrm{ZrSiO}_{4}$. It has been decided to increase up to $100 \mathrm{~s}$ the duration of the exposure. Under these conditions, the temperature at the bonding interface exceeds $1000{ }^{\circ} \mathrm{C}$ for more than $30 \mathrm{~s}$ (Figure 13). No de-bonding 
was observed, but again it is difficult to conclude because of the lack of external representative mechanical loads.

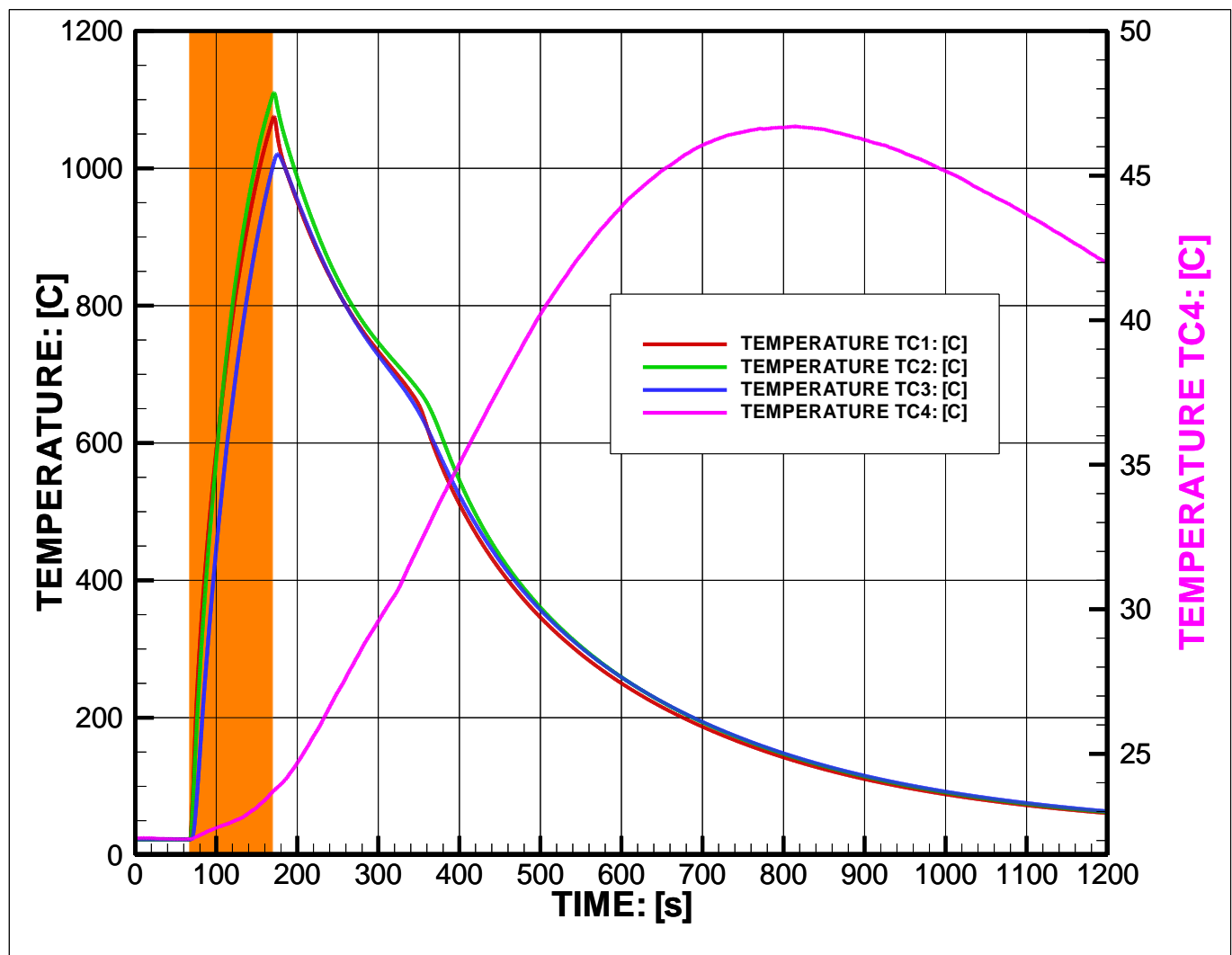

Figure 13. Measured temperature for the $\mathrm{ZrO}_{2}-\mathrm{ZrSiO}_{4}$-based adhesive hybrid breadboard.

The total mass loss for $\mathrm{ZrO}_{2}-\mathrm{ZrSiO}_{4}$-based adhesive hybrid specimen $\mathrm{N}^{\mathrm{o}} 2$ is about $4.4 \mathrm{~g}$ or $1.8 \mathrm{~g}$ additional loss compared to the test of specimen $\mathrm{N}^{\mathrm{o}} 1$ for which the duration was $40 \mathrm{~s}$ shorter (Table 10). Again, the contribution of the ablative material cannot exceed the mass loss by pyrolysis $(1.4 \mathrm{~g})$ since there was no measured ablation. The remaining mass loss can stem from the mass loss of the adhesive (by pyrolysis) and the water evaporation from the IFI. The aluminium plate at the back face experiences a larger temperature rise $\left(\sim 47^{\circ} \mathrm{C}\right.$, Figure 14) compared to the graphite-based adhesive breadboard. 


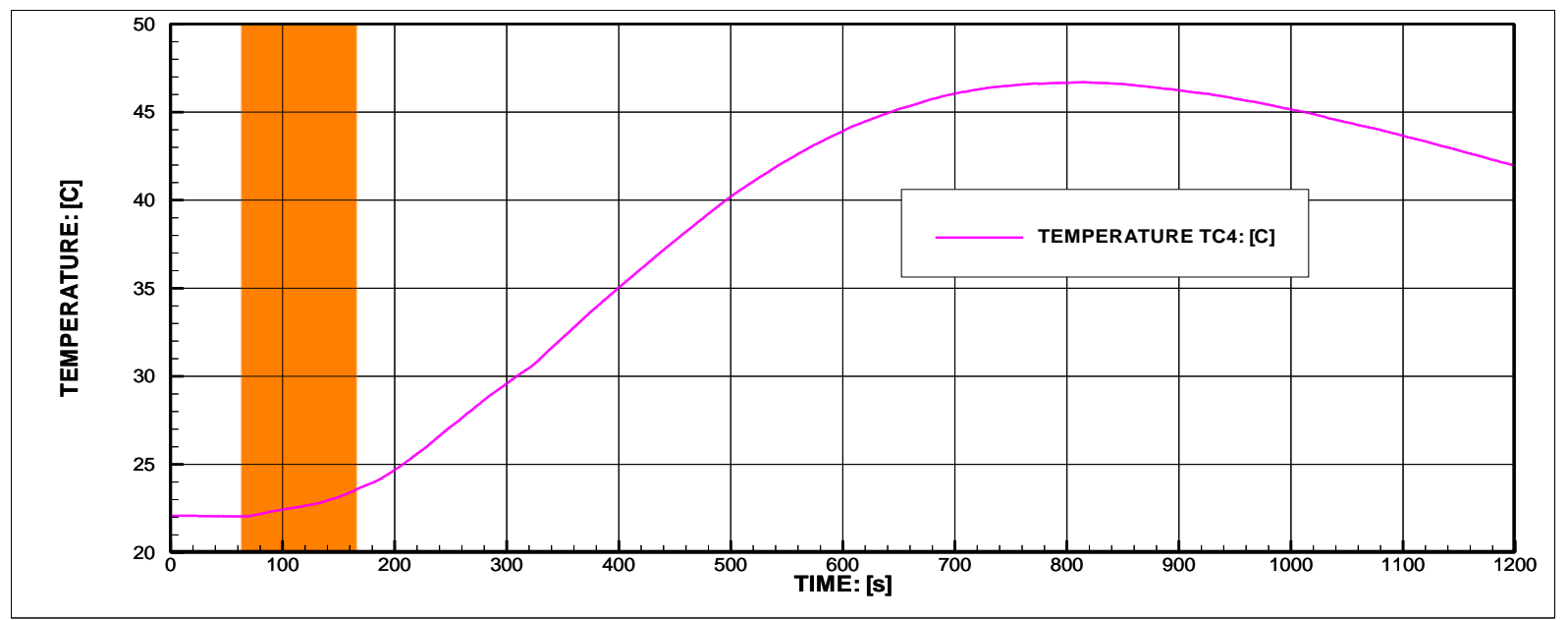

Figure 14. Measured temperature at the back face for the $\mathrm{ZrO}_{2}-\mathrm{ZrSiO}_{4}$-based adhesive hybrid breadboard.

A good agreement between simulated peak temperature and thermocouple measurements is found for both graphite-based and $\mathrm{ZrO}_{2}-\mathrm{ZrSiO}_{4}$-based adhesives (Figures 9, 11 and 13). The thermomechanical compatibility of the ablator-CMC was successfully achieved at a larger scale.

\subsection{Vibration tests}

\subsubsection{Experimental validation}

The results of the vibration, particularly the response of the evolution for the full test (for the axes $\mathrm{X}, \mathrm{Y}$ and Z) are presented in Table 11. The performance of the breadboard under vibration is normal and no significant malfunction is encountered (checked by visual inspection at anytime). It is noticed, how a sine low level is placed in-between of the random test (initially, and after partial of full test). By comparison this helps to determine if a failure or change has occurred (misplace of a bolt, crackling of the adhesive interface or failure of the stand-off brazing). The results of the comparison of these sine low levels (sweeps) are given in Tables 11-14. In these tables, low sine 1 (blue color) corresponds to the initial condition and low sine 2 (red color) corresponds to the condition after testing. As a conclusion, the breadboards (IR design) have passed the vibration test under Volna launcher specifications and under Ariane 5G (in-plane). This is very promising for the future qualification of larger breadboards and subsystems based on the hybrid concept. 
Table 11. Vibration tests data results

\begin{tabular}{|c|l|c|c|}
\hline \multirow{4}{*}{$\begin{array}{c}\text { TEST } \\
\text { AXIS }\end{array}$} & \multicolumn{1}{|c|}{ TEST } \\
DESCRIPTION
\end{tabular}


Table 12. Low Sine Comparison - Y Axis Response.

\begin{tabular}{|c|l|l|l|}
\hline $\begin{array}{c}\text { TEST } \\
\text { AXIS }\end{array}$ & \multicolumn{1}{|c|}{ TEST } \\
DESCRIPTION
\end{tabular}


Table 13. Low Sine Comparison - Z Axis Response.

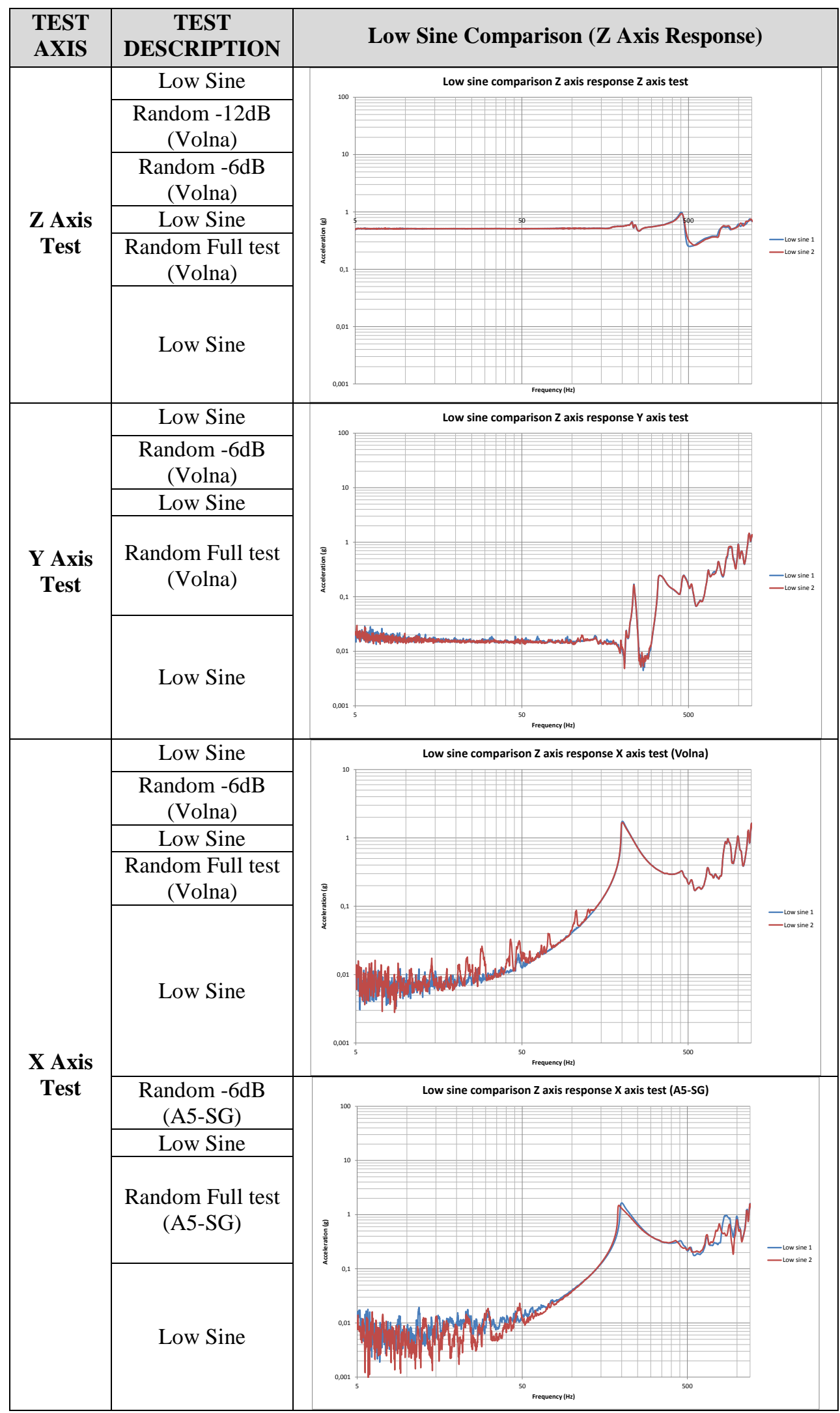


Table 14. Low Sine Comparison - X Axis Response.

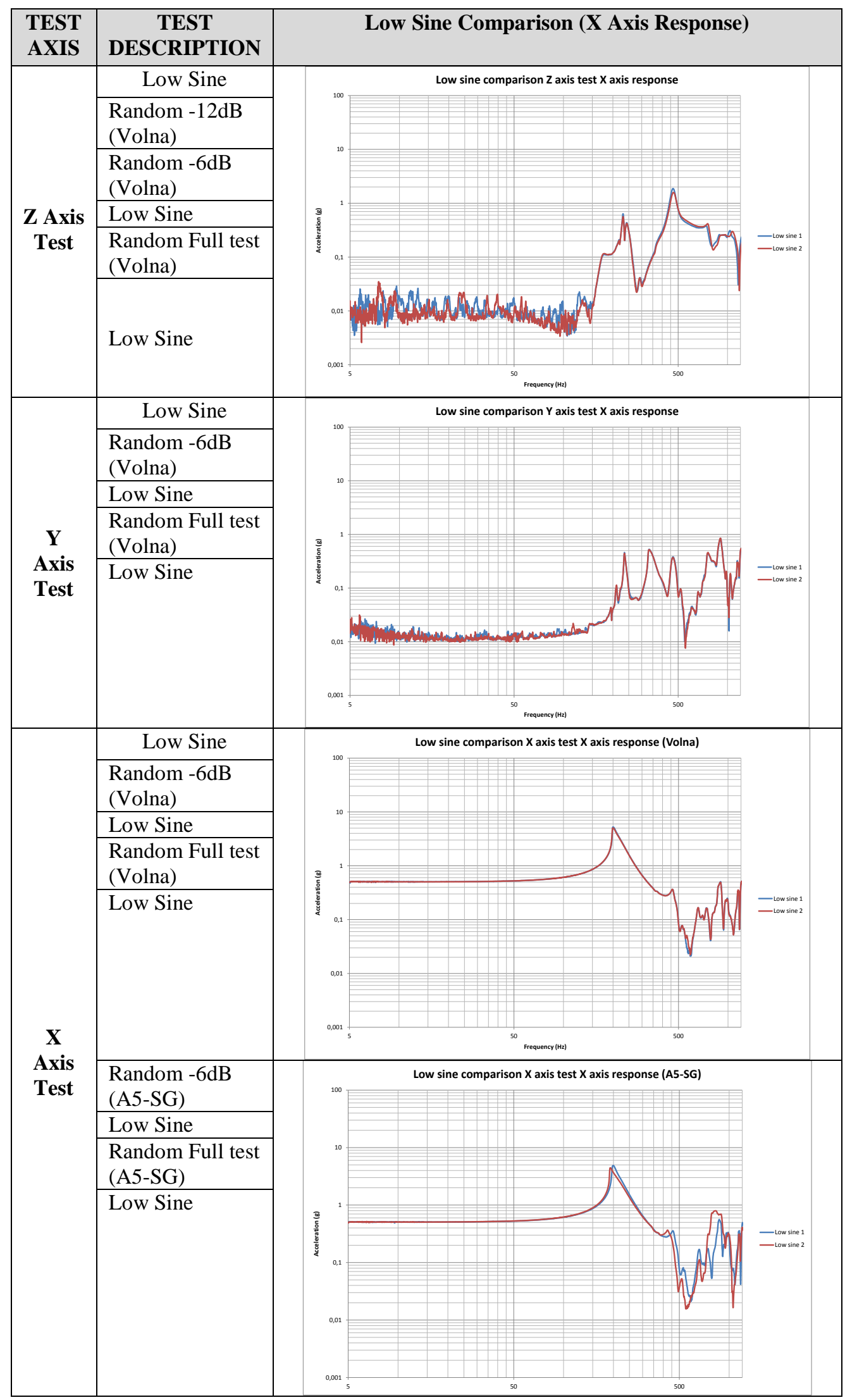




\subsubsection{Numerical simulation}

A Finite Element (FE) model was developed to calculate the natural frequencies and the normal modes of the breadboard. The idea was to compare the results obtained in the model with those measured in the vibrations tests. This way, a more in depth knowledge of the breadboard behaviour against vibrations would be available for further developments.

The FE model can be seen in Figure 15. It consists of 19,872 isoparametric, 8 nodes, solid elements, with 21,980 nodes and a total of 65,616 equations. The commercial code SOLVIA was used to develop the model and to solve it. A sparse solver with the subspace iteration method was used to find the first 20 natural frequencies and their associated normal modes.

First natural frequency was found at $200.69 \mathrm{~Hz}$ and corresponds to the bending of the stand-offs along the $\mathrm{X}$ direction. The shape of the mode can be seen in Figure 16, where the elements corresponding to the IFI material have not been represented to make it easier the identification of the mode. This result matches quite well the results from the vibration tests. In fact, the sine swept test identifies a first mode in the $\mathrm{X}$ axis at around $200 \mathrm{~Hz}$, see Table 11 results.

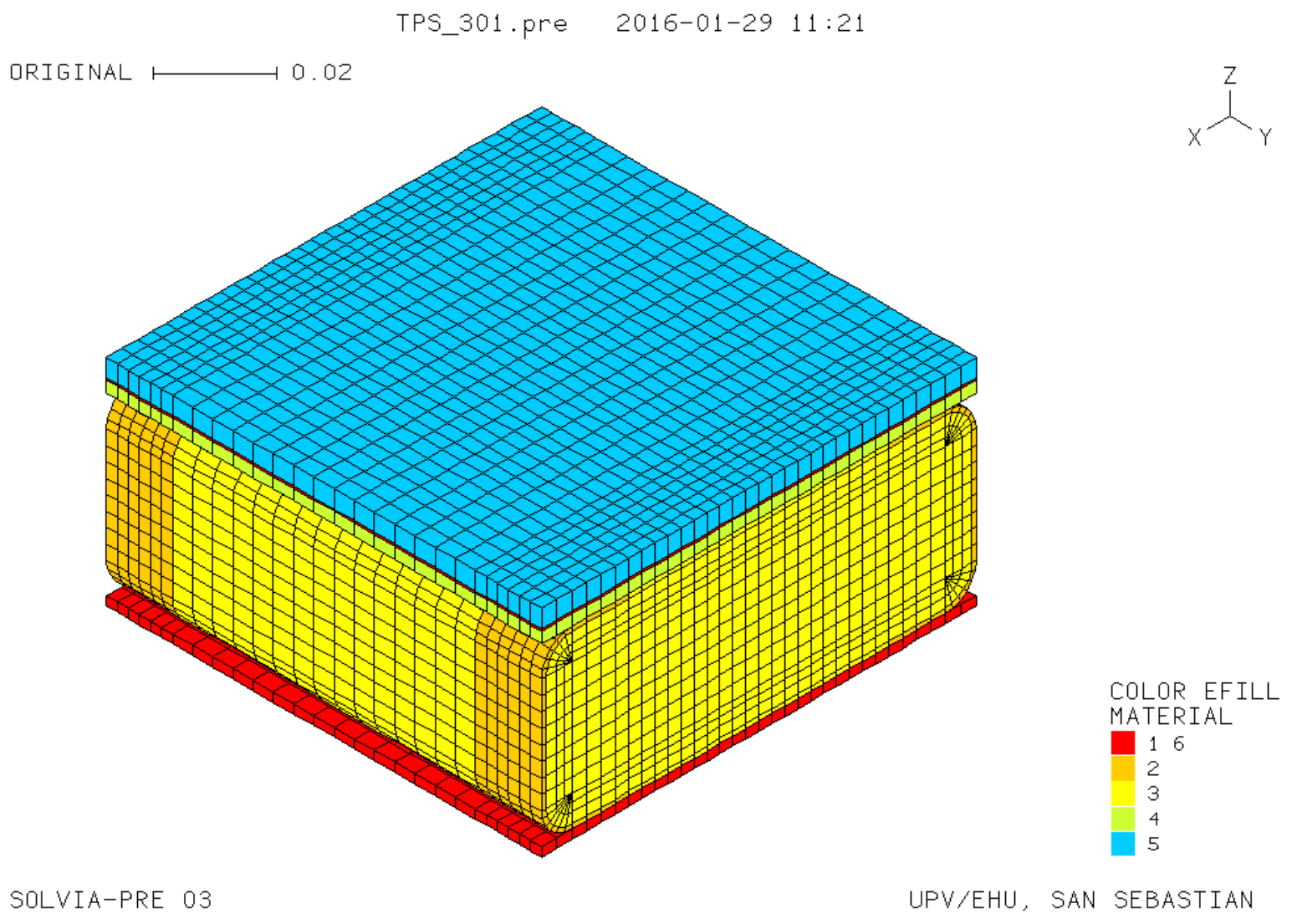

Figure 15. Finite Element model of the TPS breadboard 


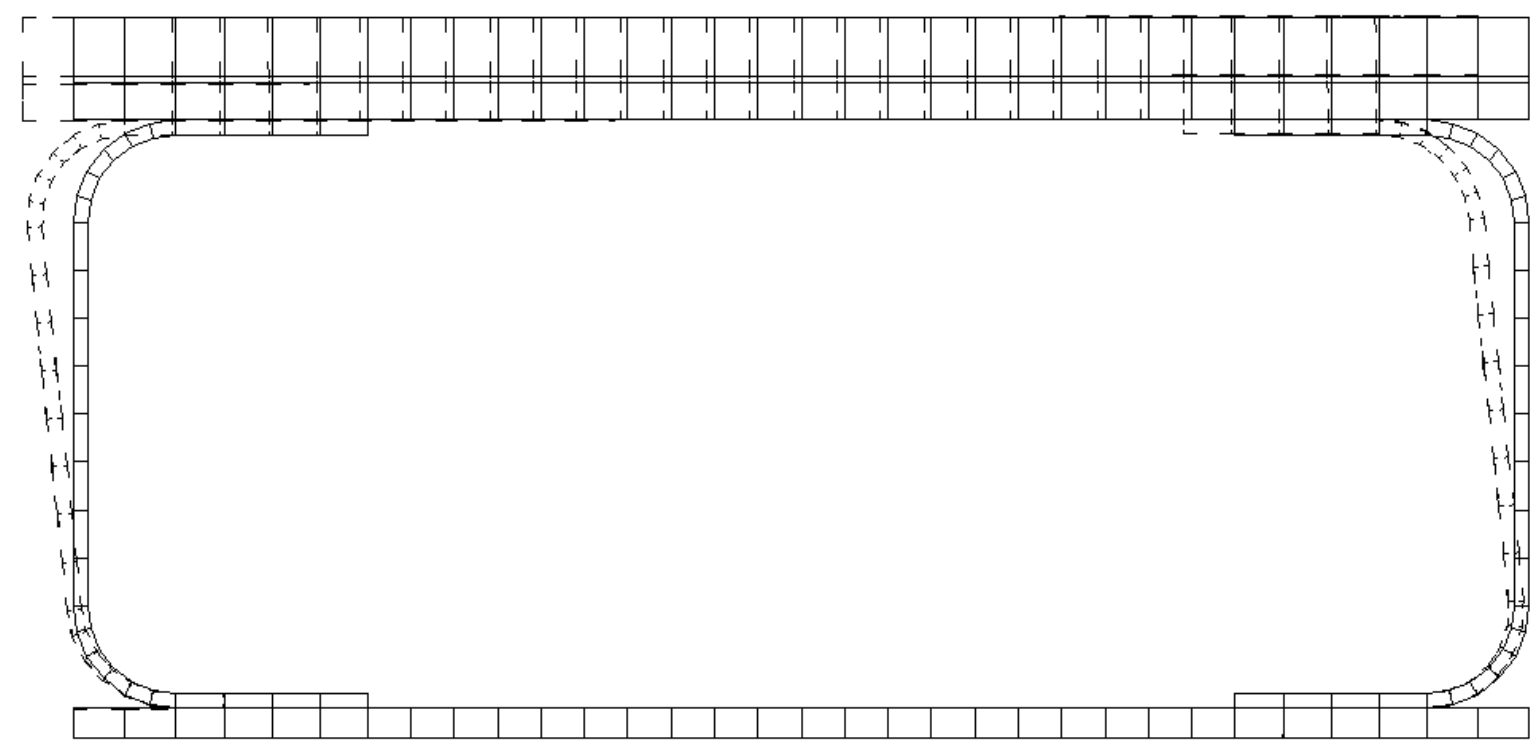

Figure 16. First normal mode of the TPS breadboard, at $200.69 \mathrm{~Hz}$

The computation in the in the $\mathrm{Y}$ direction reveals a mode at $306.25 \mathrm{~Hz}\left(10^{\text {th }}\right.$ calculated mode $)$. This mode is identified with the $320 \mathrm{~Hz}$ from the experimental swept sine test. Other intermediate modes for frequencies between $200 \mathrm{~Hz}$ and $300 \mathrm{~Hz}$ are also calculated by the FEM software, but they are attributed to bending modes with some torsion or modes with big deformation of the IFI material Finally the $\mathrm{Z}$ axis result from the test shows a normal mode at around $430 \mathrm{~Hz}$, which is not in the first 20 calculated modes. Further refinement of the model at this direction would be required.

\section{Conclusions}

A procedure for the verification of a new thermal protection system based on a hybrid ablative/resuable concept is described based on tests with representative large breadbards. Those breadboards correpond to sub-scale flat samples with assembled parts: ablative/CMC external dual layer, insulation, stand-offs and aluminum sub-structure.

Firstly, a thermal schock test has been simulated and experimentaly perfomed in order to verify the performace of the interfaces (ablator/ceramic dual layer, and ceramic/ceramic stand off ) with regard to the stresses. Thermal simulations are in close agreement with the expected results and the breadboards have passed the test. The internal insulation is able to keep the aluminum at the nominal required temperature (below $100{ }^{\circ} \mathrm{C}$ ). 
Secondly, the breaboards have been exposed to a vibration test protocol according to a common launcher profile (Volna and Ariane 5). The breabards withstood the vibration loads with to visible damage of the sub-parts and their correspoding joined interfaces. In addition simulation of the vibrational modes have been carried-out with a good agreement in the $\mathrm{X}$ and $\mathrm{Y}$ axis.

The hybrid concept looks promising in terms of of thermal performance and mass reduction. Preliminary comparisons with respect a classical fully ablative solution (keeping the substructure at a maxium of $180^{\circ} \mathrm{C}$ ) predicts that final aerial mass of the front shield is around $20 \mathrm{~kg} / \mathrm{m} 2$. The specific mass must be compared to the standard solution with ablator alone of $34 \mathrm{~kg} / \mathrm{m} 2$. The predicted gain with such hybrid system could be therefore of $40 \%$ which balance the increase in complexity.

The present manuscript shows only part of the campaign of the full verification test and to validate the concep. Further test at representative of re-entry environment (aerodynamic loads, relatively low pressure, ...) are necessary. The proposed concept has been recently tested in a plasma wind tunnel (IRS, Germany) at heatfluxes up to $5.6 \mathrm{MW} / \mathrm{m} 2$. Different duration test (80 seconds and 100 seconds) and different ablation thicknesses (10 and $12 \mathrm{~mm}$ ) have been studied. A next manuscript will be submitted soon with the results of this specific part of the campaign.

\section{Acknowledgments}

This work has been performed within the framework of the European Project "HYDRA" (G.A. n. 283797) with the financial support by the European Community.

\section{REFERENCES}

[1] Bessire B.K., Lahankar S.A, and Minton T.K., Pyrolysis of Phenolic Impregnated Carbon Ablator (PICA), ACS Applied Materials \& Interfaces 20157 (3), 1383-1395.

[2] Vallerani E, Marchese P. Fornari B, Advanced Materials for Future Aerospace Programmes. Chapter in Frontiers of Polymers and Advanced Materials. pp 29-44

[3] Pichon T., Lacoste M., Barreteau R. and Glass D. E., Integrated thermal protection systems and heat resistant structures, 2006 AIAA 57th International Astronautical Congress.

[4] Barcena J, Florez S, Perez B, Pinaud G, Bouilly JM, Fischer WPP, et al. Novel Hybrid Ablative/Ceramic Heatshield for Earth Atmospheric Re-Entry. In: Proceedings of 13th European Conference on Spacecraft Structures, Materials and Environmental Testing. Braunschweig, April, 2014

[5] Barcena, J. Florez S., Perez B., Pinaud G., Bouilly J.M., Fischer W.P.P., et al. Novel hybrid ablative/ceramic development for re-entry in planetary atmospheric thermal protection: interfacial adhesive selection and test verification plan. Proceedings of 19th AIAA international space planes and hypersonic systems and technologies conference. Atlanta (June 2014) 
[6] Triantou K, Mergia K, Marinou A, Vekinis G, Barcena J, Florez S, Perez B, Pinaud G, Bouilly JM, Fischer WPP. Novel Hybrid ablative/ceramic layered composite for earth re-entry thermal protection: Microstructural and mechanical performance. J Mater Eng Perform 2015; 24(4): $1452-1461 .$.

[7] Triantou K, Mergia K, Florez S, Perez B, Barcena J, Rotärmel W, Pinaud G, Fischer WPP. Thermo-mechanical performance of an ablative/ceramic composite hybrid thermal protection structure for re-entry applications. Comp: Part B 2015, 82: 159-165

[8] Motz G., Schmidt S.,Beyer S., "The PIP-process: Precursor Properties and Applications" in: “Ceramic Matrix Composites”, W. Krenkel Ed., May 2008, Germany, Wiley-VCH, 2008, p 165186.

[9] ASTERM Material safety datasheet, Airbus Defence \& Space, 2011.

[10] Bouilly JM. ASTERM: Maturation of a new low density ablative material. In: Proceedings of 7th European Workshop on TPS \& Hot Structures. Noordwijk, April, 2013.

[11] “CALCARB ${ }^{\circledR}$ Rigid carbon thermal insulation", Technical guide, www.mersen.com.

[12] Helber B, Chazot O, Hubin A, Magin T. Microstructure and gas-surface interaction studies of a low-density carbon-bonded carbon fiber composite in atmospheric reentry plasmas. Compos: Part A, 2015; 72: 96-107

[13] A. Stefan, G. Ionescu, G. Pelin, C.E. Pelin (Ban), I. Dinca, B. Perez, S. Florez, J. Barcena, K. Mergia, K. Triantou, C. Zuber, W. Rotaermel, J.M. Bouilly, G. Pinaud, W. Fischer., "Thermal Performance of Ablative/ Ceramic Composite”, INCAS Bulletin, vol. 6, issue 4, 2014, p. 87-101.

[14] "High temperature ceramic \& graphite adhesives", Technical Bulletin A2, AREMCO Products Inc., www.aremco.com.

[15] Hernandez, C. Jiménez, K.Mergia, P. Yialouris, V. Liedtke, C. Wilhelmi, S. Messoloras and J. Barcena, “An innovative joint structure for brazing Cf/SiC composite to Titanium alloy”, Journal of Materials Engineering and Performance 23(8) (2014) 3069-3076

[16] Pinaud G.,. Van Eekelen A.J, and Bouillyy J.-M., “Aerofast: Development Of Cork TPS Material And A 3d Comparative Thermal/Ablation Analysis Of An Apollo \& A Biconic Sled Shape For An Aerocapture Mission”, 8th International Probe Workshop, June 6-10, Portsmouth -USA, 2011. 